Article

\title{
The Role of Knowledge in Food Democracy
}

\author{
Camilla Adelle ${ }^{1,2}$ \\ ${ }^{1}$ Centre of Excellence for Food Security, University of Pretoria, Pretoria, South Africa; E-Mail: camilla.adelle@up.ac.za \\ ${ }^{2}$ Centre for the Study of Governance Innovation, University of Pretoria, Pretoria, South Africa
}

Submitted: 15 March 2019 | Accepted: 1 July 2019 | Published: 28 October 2019

\begin{abstract}
If food democracy is about who gets to determine the food that we eat and the character of the underlying food system, then we must examine not only who gets to make decisions that impact on food but also on what evidence, or knowledge, these decisions are made. This article argues that widening the democratic scope of knowledge on which our decisions on food are based is an essential component of food democracy. Food democracies do not just call for citizens to be knowledgeable about the food system but for all stakeholders to actively contribute to the holistic understanding of the food system. Four dimensions of knowledge democracy are set out: The co-production of knowledge with stakeholders; harnessing non-cognitive knowledge represented in arts and culture; knowledge as a tool for action; and the open access and sharing of knowledge. This framework is then used to explore how knowledge is currently already produced and used in a way that enhances food democracy, including through Participatory Action Research with peasant farmers, using the arts to create a 'contemplative commons' about food and the unique dialogue process through which the social movement La Vía Campesina operates. Based on these, and other, examples the article concludes that universities, and other recognized centres of knowledge production, need to focus not only on creating new knowledge partnerships but also on finding spaces to challenge and shift accepted ways of knowing in order to better promote food democracy.
\end{abstract}

\section{Keywords}

cognitive justice; community of practice; food democracy; food security; food sovereignty; indigenous knowledge; knowledge; knowledge democracy

\section{Issue}

This article is part of the issue "New Perspectives on Food Democracy" edited by Basil Bornemann (University of Basel, Switzerland) and Sabine Weiland (Université Catholique de Lille, France).

(C) 2019 by the author; licensee Cogitatio (Lisbon, Portugal). This article is licensed under a Creative Commons Attribution 4.0 International License (CC BY).

\section{Introduction}

At the core of food democracy is the idea that people can and should actively participate in shaping the food system (Hassanein, 2003; Welsh \& MacRae, 1998). Solutions to ecological, social and economic problems in the food system, it is argued, must be determined through meaningful civic participation and political engagement by informed citizens (Hassanein, 2008). The importance of individuals having equal opportunity as well as the knowledge necessary to effectively participate in decision-making is often recognized in both democratic theory as well as the literature in food democracy (Hassanein, 2008). However, the production and use of knowledge in the food system is not evenly distributed through society: Powerful economic interests seeking to maintain control over the agri-food system have limited the availability of such knowledge though intense commodification of food that distances consumers from producers (Kloppenburg, Hendrickson, \& Stevenson, 1996). At the same time, knowledge on the food system is also produced and held by recognized centres of knowledge production, such as universities and research institutes, that have traditionally held a kind of knowledge monopoly in society (Biesta, 2007). Efforts to democratize the food system, therefore, bring to the fore questions of 'whose knowledge is to be recognized, translated and incorporated into action' (Nowotny, 2003, p. 151). Democratic principles hold that all persons should not only have access to knowledge, 
but also be able to inform and shape what is considered relevant knowledge for decision making. In a world in which knowledge shapes power and voice, and vice versa (International Social Science Council, Institute of Development Studies, \& UNESCO, 2016, p. 275), food democracy does not just call for informed citizens but for them to actively contribute to the holistic understanding of the food system.

Since the 1980s and 1990s the global food system has been characterized by the consolidation and concentration of commercial food related activities to a relatively small number of (multi-national) corporations (Murphy, 2008; Pulker, Trapp, Scott, \& Pollard, 2018). This new era of corporate power has affected the way knowledge about the global food system is generated and distributed in society. For example, supermarkets have become the main point of contact between the public and the food they eat, which has distanced consumers from producers as well as the link between that food and the earth (e.g., by making certain seasonal food available all year around). Related to this, a few multi-national companies have a disproportionate hold over how issues around food are framed in the public debate (e.g., presenting supermarkets as guardians of the consumer and efficient actors in the food system; Pulker et al., 2018). These multi-national companies also hold a huge amount of data on the food system (e.g., on consumer purchasing patterns through loyalty cards), which is not released into the public domain. In addition, global patent laws such as Trade Related Aspects of Intellectual Property Rights restrict access to knowledge to companies with access to patent courts (e.g., Monsanto owns over 90 per cent of genetically engineered seeds in commercial use; Financial Times, 2006, as cited in Murphy, 2008).

Other more recognized centres of knowledge production and transfer (such as universities, higher education and research institutions) have also had a profound impact on the production and transfer of knowledge about the food system. Specifically, these institutions have traditionally played an instrumental role in determining what counts as relevant, or scientific, knowledge. While these knowledge institutions can no longer be regarded as having the monopoly on knowledge (as seen above in the huge data sets held by private food companies), there is still a strong tradition in which knowledge from the university is understood as being of a special kindmore true, more real, more rational than other types of knowledge from outside the hallowed halls of academia (including traditional, lay or corporate knowledge; Biesta, 2007). The upshot of this interpretation is that there is only one way to see and understand the world that is valid.

The concept of knowledge democracy, in contrast, involves the acceptance of a diversity of different forms of knowledge including lived experience and every day practice as well as artistic or other forms of representations that are accessible to a lay person (Santos, 2006). Over the last few decades there has been a growing awareness that there is an inequality in the world of knowledge: 'Certain dominant knowledge institutions and knowledge perspectives have been shaping the global socioeconomic order' (Tandon, Singh, Clover, \& Hall, 2016, p. 21). Gaventa and Cornwall (2006, p. 122) argue that knowledge and power are closely intertwined and knowledge production, use and dissemination determines what is 'conceived as important, as possible, for and by whom...Asymmetric control of knowledge production, of 'others' can severely limit the possibilities that can be imagined or acted upon' (Gaventa \& Cornwall, 2006, p. 122). This suggests that scientific knowledge, although vital, is not the only relevant knowledge that is important in decision making (Blowers, Boersema, \& Martin, 2005). According to Freire (2000), knowledge democracy focuses on demystifying power in the process of knowledge creation, dissemination and use to bring liberation of both the oppressed and the oppressor. From the point of view of food democracy, embracing a plurality of perspectives by, for example, opening up the process of 'doing science' and by bringing consumers closer to the producers of the food that they eat, is a moral imperative to include subaltern forms of knowledge into decision making. It is, however, also a practical necessity as it ensures the production of holistic and pluralistic knowledge that is better able to address complex problems, such as food insecurity that cut across a number of economic sectors, levels of governance as well as involve a wide array of actors both inside and outside of government (Nowotny, Scott, \& Gibbons, 2001; Pereira \& Ruysenaar, 2012).

This article brings together literatures on knowledge democracy and food, including literatures on food sovereignty (e.g., Martínez-Torres \& Rosset, 2014), food governance (e.g., Matacena, 2016), alternative food networks (e.g., Harper, Shattuck, Holt-Giménez, Alkon, \& Lambrick, 2009), and agro-ecology (e.g., Méndez, Bacon, \& Cohen, 2013). It does so in order to illustrate how widening the democratic scope of knowledge on which our decisions on food are based is an essential component of food democracy. According to Tandon et al. (2016), knowledge democracy is best understood as an interrelationship of phenomena, which they set out in four dimensions, namely: Cognitive justice and the coproduction of knowledge; multiple representations of knowledge; knowledge as a tool for action; and knowledge sharing. While the boundaries between these four dimensions of knowledge democracy can be somewhat blurred in practice, the different dimensions provide a useful lens through which to unpack the role of knowledge in food democracy. In the next four sections of this article each of these dimensions of knowledge democracy is explored and illustrated with examples of how knowledge is already beginning to contribute to the pursuit of food democracy around the world. Where possible the examples are taken from the literature. Examples are also reported from the author's experiences of the food security research in South Africa. In the final and 
concluding section the role that universities and other recognized sites of knowledge production could play in further encouraging food democracy through deepening knowledge democracy is discussed.

\section{Cognitive Justice and the Co-Production of Knowledge}

The concept of knowledge democracy not only recognizes the right of different forms of knowledge to co-exist but argues that this plurality must be actively recognized and embraced (Visvanathan, 2009). This idea of 'cognitive justice' presupposes that knowledge is embedded in ecologies of knowledge 'where each knowledge has its place, its claim to a cosmology, its sense as a form of life' and cannot be abstracted from its culture (Visvanathan, 2009, p. 22). Opening up what is understood as 'the truth' to include non-cognitive knowledge embedded in the stories, culture, ceremonies and day to day experiences of the majority of the people of the world is a moral imperative to address inequalities in the dominant Western paradigm of scientific knowledge (Oswald, 2016; Hall \& Tandon, 2017). It is also essential to counter the tight grip on knowledge held by multi-national corporations, especially in the agri-food system. Furthermore, opening up the scope of what is considered valid knowledge is also pragmatic: Pluralistic knowledge regimes also provide diverse 'communities of problem solving' to find workable solutions to some of society's most complex problems (Visvanathan, 2009). In addition, knowledge created with the involvement of the ultimate users and/or beneficiaries of that knowledge is more likely to be seen as legitimate and relevant (Oswald, Gaventa, \& Leach, 2016).

Rather than shifting the prioritization from one form of knowledge to another (whether indigenous or experiential etc.), realizing cognitive justice calls for the co-production of knowledge-a collaborative process bringing together multiple kinds of knowledge and perspectives to construct an understanding based on a plurality of situated knowledges (Oswald et al., 2016). According to Nowotny et al. (2001) in Re-thinking Science: Knowledge and the Public in an Age of Un-certainty, this process moves beyond producing merely scientifically reliable knowledge towards socially more robust knowledge that is repeatedly tested and modified in the real world through the perspectives of an extended group of experts including lay people (i.e., outside of science). Expertise is therefore spread throughout society and democratized rather than in the hands of the elite (Nowotny, 2003) either in universities or large corporations.

Transdisciplinary and participatory research approaches that value and integrate different types of knowledge systems have become particularly associated with research into ecosystems management and sustainable food production. Farmers across the world are continuously adapting and developing their knowledge to cope with local manifestations of global envi- ronmental change (Tengo, Brondizio, Elmqvist, Malmer, \& Spierenburg, 2014). Consequently, the importance of indigenous knowledge has come to the fore, for example, when thinking through climate change adaption strategies in traditionally rain fed agricultural regions (e.g., Food and Agriculture Organization, 2009; Ncube, 2018). Similarly, agro-ecologists, since the 1980s, have valued and sought to better understand the experiential knowledge of farmers as a necessary component to develop a more sustainable agriculture (Méndez et al., 2013). According to the 'Réseau Semences Paysannes' in France, agro-ecological knowledge production 'can be carried out only in liaison with peasant movements which use agroecology' (Réseau Semences Paysannes, 2008, as cited in Levidow, Pimbert, \& Vanloqueren, 2014, p. 1134, emphasis added). This type of transdisciplinary agro-ecological research fits well with participatory approaches and an increasing number of agroecological studies in the last decade have used these approaches in different ways (e.g., Altieri \& Toledo, 2011; Bacon, Méndez, Gliessman, Goodman, \& Fox, 2008). Levidow et al. (2014) argue that going beyond the linear transfer of research and technology from science to farmers to a more balanced farmer-scientist alliance based on the co-creation and exchange of knowledge is critical in agroecology moving beyond being just a scientific discipline to a transformative role in the food system).

Beyond food production, the co-construction of knowledge in other components of the food system (such as processing, distribution, retail, consumption and waste) has commonly been employed for problem solving that directly or indirectly feeds into policy formulation. For example, Food Policy Councils (FPCS), seek to convene and leverage off the collective knowledge of a wide variety of food systems actors and stakeholders (Haysom, 2014). FPCs can be defined as structures that bring 'together stakeholders from diverse food-related areas to examine how the food system is working and propose ways to improve it' (World Hunger Year, 2008, as cited in Kent, 2011, p. 142). Information exchange and the sharing of perspectives across different sectors and parts of the food system are important activities of these councils (Schiff, 2008) contributing to their role of creating 'democratic spaces for convergence in diversity' and sites of social learning (Harper et al., 2009, p. 7). However, because FPCs aim to identify and propose innovative solutions to improve local or state food systems, they often engage in food system research in order to make their policy recommendations. One of the first activities of many new councils is to participate in collaborative efforts to generate and publish some type of food system assessment (Harper et al., 2009; Schiff, 2008). FPCs also commonly publish information brochures and food guides to educate the public and other government officials (Schiff, 2008).

The co-production of knowledge for food policy can also come from more ad hoc fora. For example, the Western Cape Food and Nutrition Strategic Framework 
(Western Cape Government, 2016) in South Africa was drafted on the basis of a series of stakeholders meetings steered by a team of local food security researchers and policy. Rather than relying on a purely academic (or policy) driven approach, the strategy's themes and underlying actions were developed through a dynamic participatory process. This was designed to create opportunities for stakeholders to put forward their perspectives of the food security problems and possible solutions on the ground in a 'very wild and woolly process with all kinds of emergent stuff happening' (personal communication with a policy official, Cape Town, May 15, 2017). The role of the science and policy team was to collect as many ideas as possible in 'a living breathing document' (personal communication with an academic, Cape Town, November 1, 2017) with '[t]he hope...that by enlisting people that were embedded in the various parts of the system...that they would...be more knowledgeable about the topics that we were going to include into the policy' (personal communication with a policy official, Cape Town, May 15, 2017). Thus stakeholders were not just consulted on a draft policy, as is legally constituted in South Africa, but participated in the co-production of knowledge of the food security policy problem and possible solutions in their local area.

\section{Multiple Representations of Knowledge}

The concept of knowledge democracy defines knowledge in broader terms than just peer-reviewed journal articles and books to include not only the 'facts,' but also the feelings, experiences and consciousness or familiarity linked to activities of our daily lives and often articulated in the arts (Tandon et al., 2016):

Knowledge is created through research, through the experience of the wise, through the act of surviving in the world, and is represented in text, poetry, music, political discourse, social media, speeches, drama and storytelling. Knowledge is linked to practical skills, to our working lives and to universal and abstract thought. Knowledge is created every day by each one of us and is central to who we are as human beings. (Escrigas, Sanchez, Hall, \& Tandon, 2014, p. XXXIII)

Clover (2006, 2012) cited in Tandon et al. (2016) argues that the arts are well placed to facilitate knowledge mobilization due to a number of characteristics of the arts: For example, the versatility of art genres, which allows flexibility in revealing and representing a wide range of issues and also the universal nature of the arts so that every people and culture around the world has their own types of artistic expression and custom. In addition, the arts allow the imagination to soar above the, often mundane, constraints of the everyday so that the world can be imagined and re-imagined in new ways creating new forms of knowledge. Clover goes on to argue that the symbolic and metaphorical nature of art allows meanings that go beyond the limitations of mere words and language and so helps to make fresh connections between ideas and understanding.

Beyond the arts, Tandon et al. (2016, p. 26) argue that "knowledge is also created, represented and shared through age old practices such as ceremonies of indigenous people, and the sharing of stories that keep alive cultural practices and ways of knowing that would otherwise be erased.' While the representation of knowledge through stories and customs is often associated with the indigenous knowledge of marginalized communities, ethnographic studies of workplace practices show organizational knowledge can also be represented and shared in similar ways and that this knowledge can play a significant role in (situated) institutional learning (Brown \& Duguid, 1991).

Capturing and integrating this non-cognitive knowledge within the current scholarly knowledge system is problematic. One approach is to employ Visual Participatory Methods for science-community engagement. For example, in the 'Heart of the Matter' project community members from Delft township in Cape Town were trained in photo-voice techniques in order to exchange perspectives on food preferences and habits with disease research scientists from nearby Stellenbosch University (Sustainable Livelihood Foundation, 2016). Photovoice is a qualitative method in which participants are asked to express their points of view and/or represent their communities by photographing and interpreting scenes that highlight research themes. The photovoices were published as a report along with the scientists' reflections on the interaction. The scientists felt that they had learnt from the experience, which had given them 'a new perspective,' 'a great learning experience,' and 'insight that the laboratory cannot offer' (Sustainable Livelihood Foundation, 2016, pp. 51-53). This enhanced understanding included both cognitive and non-cognitive knowledge: The photo-voices illustrated the complexity as well as the constant negotiation process involved in food choice and health on a daily basis that 'involves consideration of budget, contingency, health, safety and convenience' (Sustainable Livelihood Foundation, 2016, p. 53). One scientist explained how they had been 'really impressed by how the photographers succeeded in portraying something really complex by means of what on face value appears to be a very simple and straightforward image' (Sustainable Livelihood Foundation, 2016, p. 53). The scientists also connected emotionally with the photo-voices: 'When looking at the photos and the narratives, I felt as if I was transferred into their lives at that moment, which was a truly moving experience' (Sustainable Livelihood Foundation, 2016, p. 53). The use of these visual methods therefore allowed deeply personal stories to be articulated using non-verbal expression of emotional truths that are difficult to communicate in words. In turn, this provided the scientists with a deeper human understanding of the problem that their research was attempting to address. 
Other examples of the use of the arts to engage with non-academic communities on food issues often aim to mobilise knowledge by using art to stimulate or provoke different kinds of dialogue and modes of engagement. For example, the 'Food (R)evolutions' exhibition, which travelled to several African and European cities, blended photography and videos, narrative theory and contemporary perspectives on African food systems (Meyer \& Lindow, 2016). Similarly, the 'ARThropocene' project engaged in 'artful science and scienceful art' by encouraging participants to view an art exhibition before taking part in a dialogue, facilitated in part by the artists, in order to provoke different kinds of encounters and collaboration on the topic of food (Preiser, Hamann, \& Biggs, 2017). The intention was for the 'alternative' mode of ('artful') inquiry would help the participants 'flex/stretch their imagination as transformative capacity towards anticipating alternative Anthropocene futures' (Preiser et al., 2017).

Drama and poetry can also help create 'a contemplative commons' to develop the worldviews, mindsets, and social practices supportive of the social change. A play commissioned by the Centre of Excellence for Food Security in South Africa entitled Another One's Bread and performed in theatres in Cape Town and Johannesburg tied together issues of food, funerals and feeding schemes in the townships by embedding them in cultural context and humour 'that tows along facts and ideas in its wake' (Stones, 2018). Similarly, a collection of poetry and prose about food entitled Cutting Carrots the Wrong Way explores the social meanings of food and the ways in which these meanings are lived out through individuals, culture, the media and traditional systems. Such meanings, the editor of the volume argues, can 'better be explored through a multi-disciplinary humanities approach' that views food systems as sites of cultural performance, social resistance and aesthetic expression (Moolman, 2017, p. 7).

\section{Knowledge as a Tool for Action}

Another central tenant of knowledge democracy is harnessing the powerful agency of individual realization that 'their knowledge' counts (Tremblay \& Jayme, 2015). Hall (2011) refers to knowledge democracy as a 'global knowledge movement' that is action-orientated and recognizes, gives visibility to and strengthens the knowledge that is created in the context of people trying to 'change the world.' Knowledge is therefore seen as a powerful tool for taking action in social movements and to deepen democracy in order to build a fairer and healthier world (Tandon et al., 2016). For some commentators, knowledge democracy for community transformation is best brought about through collaborative research approaches such as Community Based Participatory Action Research (Openjuru, Jaitli, Tandon, \& Hall, 2015). However, Hall (2011, p. 4) reminds us that knowledge for action does not have to happen within the context of formal research (collaborative or otherwise) but instead can be driven by the people themselves 'who are seeking recognition of their rights, their land claims, access to jobs, ecological justice, recovery or retention of their languages.' Knowledge within such a movement formation is most likely place-based and rooted in the daily lives of people who increase their knowledge of their own contexts and 'by sharing what they are learning with allies and others like themselves moves...towards being agents in the naming of the world' (Hall, 2011, p. 4).

Such (re)appropriation and sharing of indigenous knowledges to activate a potent movement is notable in the knowledge strategy of La Vía Campesina-the most prominent member and driving force of the food sovereignty movement. According Martínez-Torres and Rosset (2014), the La Vía Campesina has utilized a process called Diálogo de Saberes in Spanish, which roughly translates to 'dialog among different knowledges and ways of knowing,' to harness the diverse knowledges of its large grassroots membership. Diálogo de Saberes begins with the recognition, recovery and valorisation of local and or traditional knowledges (Leff, 2011, as cited in Martínez-Torres \& Rosset, 2014). In the dialogue process 'different visions and cosmovisions' are shared on a horizontal equal-footing and one knowledge is not imposed on others (Martínez-Torres \& Rosset, 2014, p. 979). This process is distinguished from stakeholder mediations where the goal or outcome is a compromise solution whose mid-point position reflects the geometry of power (Massey, 1991). Rather than finding a midpoint, Diálogo de Saberes allows 'new theoretical and political discourses to be invented that interweave, hybridize, mimic and confront each other in a dialogue between communities and academy, between theory and praxis, between indigenous and scientific knowledge' (Leff, 2004, in Martínez-Torres \& Rosset, 2014). Diálogo de Saberes has therefore allowed for areas of internal consensus to be reached, often in the form of new 'emergent' proposals and ideas, which help steer the conceptualisation and strategic direction of the food sovereignty movement as well as maintain internal cohesion (Martínez-Torres \& Rosset, 2014). According to Martínez-Torres and Rosset (2014), the dialogue process has in this way accelerated the recent shift in the movement toward the promotion of agro-ecology, which is simultaneously seen as a field of academic research, a set of practices and a social movement (Wezel \& Soldat, 2009).

\section{Knowledge Sharing}

Knowledge democracy is also about open access for sharing knowledge so that everyone that needs it has access (Tandon et al., 2016). Since the creation of Oxford University and other early tertiary education institutions in Europe some 500 years ago, access to knowledge has been limited (Hall \& Tandon, 2017). The creation of the university system had the effect of 'enclosing knowl- 
edge...exerting a form of control over knowledge and providing a means for a small elite to acquire this knowledge for the purposes of leadership of a spiritual, governance or cultural nature' (Hall \& Tandon, 2017, p. 8). The walls of the universities quite literally came to demark the 'knowers' on the inside and the 'non-knowers' on the outside (Hall \& Tandon, 2017, p. 8). Western research is steeped in a monolithic understanding of knowledge that assumes individual ownership of knowledge enabling exploitative practices that can co-opt and distort indigenous ways of knowing (Oswald, 2016). Traditional or lay knowledge, in contrast is often communally owned seeing knowledge as a common good (Lucio-Villegas, 2016). Although universities, and other research centres, still play an important role in the definition of what counts as 'scientific' knowledge, they no longer hold the monopoly on research or data (Biesta, 2007). Nowadays, research is conducted and data collected in many places outside of the University. For example, the private sector increasingly (and tightly) holds huge volumes of data on purchasing patterns of their consumers.

One way to break down the walls between 'expert' and 'lay' knowledge is through Communities of (food) Practice made up of networks of individuals, organisations and institutions that come together to share knowledge and experiences on an ongoing basis (Wenger, 2000). Communities of (food) Practice can fulfil a variety of related functions. They can: connect people who might not otherwise have the opportunity to interact; provide an opportunity to share information; help people organize around purposeful action, stimulate learning through the transfer of knowledge from one member to another; and generate new shared knowledge that helps people transform their practice (Cambridge, Kaplan, \& Suter, 2005). Like FPCs, Communities of (food) Practice are particularly useful in linking multiple levels, economic sectors and actors that have (an often hidden) influence on food in our society. In contrast to most FPCs however, Communities of (food) Practice do not aim to directly inform decision making and policy as their informal make up rarely carries any mandate from a government body neither do they claim legitimacy to speak on food issues for a certain community or geographical area. Rather the participants learn from the different experiences and perspectives of other Communities of (food) Practice members creating a unique opportunity to inform their food related practice beyond the Community of (food) Practice (Food Secure Canada, 2011).

Knowledge exchange and collective learning can also take place in informal knowledge networks that are not deliberately constructed and labelled as such. For example, Alternative Food Networks (such as veggie box schemes, farmers markets, and cooperatives) help to generate knowledge exchange in a process that brings consumers, producers and other food actors closer together. Whereas the corporate control of the food system brought about through increasing commodification as well as vertical and horizontal integration limits infor- mation availability to consumers about the products that they buy, Alternative Food Networks tend to shorten the distribution channels (Hassanein, 2008). This can be used to make sure that the products reach the consumers with information so that they can find out where their food is produced, by whom and how (Darlot, Lamine, Brandenburg, Alencar, \& Abreu, 2016). Alternative Food Networks can also link producers in a given geographical area generating a collective learning process that leads to a rapid diffusion of knowledge, best practice and innovation while also providing avenues to retain traditional knowledges (Beckie, Kennedy, \& Wittman, 2012). Many Alternative Food Networks also attempt to (re-)educate consumers so that they can 'resist accepting and conforming to the offer of the conventional system' (Darlot et al., 2016, p. 2). The standardised industrial food system, it is argued, has deskilled and pampered the consumer through a proliferation of packaged convenience food often available out of season (Darlot et al., 2016; Matacena, 2016). By re-embedding food production, distribution and consumer practices in a social and spatial sense (Matacena, 2016) these networks can not only promote a new social economy of food that will make a difference to only a handful of people, but disseminate new ways of knowing, growing and organizing food using horizontal networks of knowledge sharing and learning (Goodman, DuPuis, \& Goodman, 2012).

Cultivating knowledge networks is all very well when the holders of relevant knowledge are keen to collaborate and engage in collective learning. However, private companies, and even the parts of governments with which they engage, are not always ready to share information that they regard as economically sensitive. In these cases, a different approach is needed to promote greater transparency and debate on the food system. For example, the Land Matrix launched in 2012 as an open data tool to monitor land deals around the world. It is intended to enhance governance decisions on land resources through raising awareness and public empowerment. The online tool is facilitated by a partnership of academic and development organizations but aims to also involve the public in building a constantly evolving data-base through crowd-sourcing (Anseeuw, Lay, Messerli, Giger, \& Taylor, n.d.). The data come from a variety of sources that include media reports, reports by international organizations and non-governmental organizations as well as academic research based on field research projects (Anseeuw et al., n.d.). By providing access to previously hidden data and restricted sources on large scale land acquisition the Land Matrix is hoped to enhance the quality of land governance via the empowerment of populations: Transparency and information openness is intended to help local populations identify projects, see how funds are spent and learn about the purpose, costs and results of land acquisitions. The chance of damaging activities being uncovered is also hoped to incentivize companies and governments to adapt their practices (Anseeuw et al., n.d.). 


\section{Conclusions}

At the core of food democracy is a criticism of the dominant role of large corporations play in food and the idea that all people should have the power to help shape the food system (Hassanein, 2003; Norwood, 2015). Viewing the food system through the lens of knowledge democracy (where knowledge is seen as a kind of power), this article argues that not only do citizens need access to knowledge in order to make decisions about the agrofood system but they also must be able to inform and shape what is considered relevant knowledge for decision making. This ideal is far from the current state of knowledge in the food sector, where consumers are distanced from producers and where universities traditionally act as gate-keepers on what is considered as scientific (rational) knowledge. However, Hassanein (2003, p. 78) reminds us that there are already spaces of resistance and creativity in which people themselves attempt to govern and shape their relationships with food and agriculture.' This article attempts to unpack some of these spaces by examining the role of knowledge and giving examples of how opening up the scope of knowledge is already starting to assist citizens to determine policies and practices that shape of the food system in their communities, regions and countries.

Goodman et al. (2012) argue that shared knowledge and mutual understanding between producers and consumers are the foundation of alternative food systems. However, more inclusive knowledge processes will not automatically result in consensus on what kind of food system we should aim towards, nor how best to get there. It is unlikely that common ground will easily be found across cultures, socio-economic backgrounds, political persuasions and differential power relations. Accepting a diversity of knowledges on equal terms means embracing a dialogic process, characterized by an intense (perhaps endless) conversation between proponents of different knowledges and ways of knowing (Nowotny, Scott, \& Gibbons, 2003, p. 187). Facilitating these conversations requires creating a 'new architecture of knowledge' (Dolan et al., 2016) that makes spaces to shift accepted ways of knowing and embraces new knowledge partnerships.

Universities are ideally placed to help create this new architecture of knowledge since, in contrast to private companies, they have a civic role in producing knowledge for the good of society rather than for competitive advantage in the market place. The idea that universities should play a role in democracy and democratisation goes back to the Enlightenment and the beginnings of the modern nation state (Biesta, 2007, p. 478). Under this traditional model the civil role of universities was that of knowledge generation and transfer (Weymans, 2010). In contrast, the examples given in this article illustrate the many non-traditional knowledge roles universities are now playing in relation to food and agriculture. Cultivating research partnerships, sharing knowledge and data, as well as and the coproduction of knowl- edge with a variety of actors outside of science are at the heart of universities' emerging contribution to deepening food democracy. This 'challenges universities to be of and not just in the community; not simply engaged in "knowledge-transfer" but to establish a dialogue across the boundary between the university and its community which is open ended, fluid and experimental' (Watson, 2003, as cited in Millican \& Hart, 2011, p. 3). Universities then become sites of public discourse rather than sites of exclusive expertise (Delanty, 2003). According to LucioVillegas (2016), encouraging this kind of grass-roots activity that aims to make connections between different types of knowledge can bring the university down from its ivory tower. Universities must start to think, 'not only about justice in the larger world, but also about their own distinctive role in shaping cognitive justice and knowledge democracy' (Gaventa \& Bivens, 2014, p. 149).

Individual researchers can also reflect on their own role in creating knowledge. Oswald (2017) argues that researchers are in a privileged position because they can set the research agenda, ask certain questions, and involve certain people. If we are all experts now, the ordering of this brave new world of pluralistic expertise will be played out and negotiated in these new (knowledge) spaces (Nowotny, 2003). In these 'problem-generating and problem-solving' environments competing experts, institutions will vie with each other, as well as 'variously jostling publics' to bring their knowledge to bear on decisions (Nowotny, 2003, p. 156). Negotiating shared knowledge and meaning in these spaces as we collectively produce, disseminate and use new knowledge to inform decisions about our food systems will no doubt be a messy and, at times, chaotic process, but it is an essential part of food democracy.

\section{Acknowledgments}

I would like to thank the two anonymous reviewers and the editors for their helpful comments on earlier drafts of the manuscript. This research is funded by the Centre of Excellence for Food Security, South Africa.

\section{Conflict of Interests}

The author declares no conflict of interests.

\section{References}

Altieri, M. A., \& Toledo, V. M. (2011). The agroecological revolution in Latin America: Rescuing nature, ensuring food sovereignty and empowering peasants. Journal of Peasant Studies, 38(3), 587-612.

Anseeuw, W., Lay, J., Messerli, P., Giger, M., \& Taylor, M. (2013). Creating a public tool to assess and promote transparency in global land deals: The experience of the Land Matrix. The Journal of Peasant Studies, 40(3), 521-530. https://doi.org/10.1080/03066150. 2013.803071 
Bacon, C. M., Méndez, V. E., Gliessman, S. R., Goodman, D., \& Fox, J. A. (Eds.). (2008). Confronting the coffee crisis: Fair trade, sustainable livelihoods and ecosystems in Mexico and Central America. Cambridge, MA: MIT Press.

Beckie, M. A., Kennedy, E. H., \& Wittman, H. (2012). Scaling up alternative food networks: Farmers' markets and the role of clustering in western Canada. Agriculture and Human Values, 29(3), 333-345.

Biesta, G. (2007). Towards the knowledge democracy? Knowledge production and the civic role of the university. Studies in Philosophy and Education, 26(5), 467-479.

Blowers, A., Boersema, J., \& Martin, A. (2005). Experts, decision making and deliberative democracy. Environmental Sciences, 2(1), 1-3.

Brown, J. S., \& Duguid, P. (1991). Organisational learning and communities of practice: Towards a unified view of working, learning and innovation. Organizational Science, 2(1), 40-57.

Cambridge, D., Kaplan, S., \& Suter, V. (2005). Community of practice design guide: A step-by-step guide for designing \& cultivating communities of practice in higher education. Louisville, CO: EDUCAUSE. Retrieved from https://library.educause.edu/ resources/2005/1/community-of-practice-designguide-a-stepbystep-guide-for-designing-cultivatingcommunities-of-practice-in-higher-education

Darlot, M. R., Lamine, C., Brandenburg, A., Alencar, M., \& Abreu, L. S. (2016). Alternative food networks and new producer-consumer relations in France and in Brazil. Ambiente \& Sociedade, 19(2), 1-22.

Delanty, G. (2003). Ideologies of the knowledge society and the cultural contradictions of higher education. Policy Futures in Education, 1(1), 71-82.

Dolan, C., Shahrokh, T., Edström, J., King Kabafunzaki, D., Maganya, D., Moninga, A., \& Onen Ongwech, D. (2016). Engaged excellence or excellent engagement? Collaborating critically to amplify the voices of male survivors of conflict-related sexual violence. IDS Bulletin, 47(6), 37-54. Retrieved from https://opendocs.ids.ac.uk/opendocs/bitstream/ handle/123456789/12747/IDSB47.6_10.1908819682016.198.pdf?sequence $=1$

Escrigas, C., Sanchez, J. G., Hall, B., \& Tandon, R. (2014). Editor's introduction. In Global University Network for Innovation (Ed.), Knowledge, engagement and higher education: Contributing to social change (pp. XXXI-XXXIX). Hampshire and New York, NY: Palgrave Macmillan.

Food and Agriculture Organization. (2009). FAO and traditional knowledge: The linkages with sustainability, food security and climate change impacts. Rome: Food and Agriculture Organization.

Food Secure Canada. (2011). Food democracy and governance (Discussion Paper No. 10). Montreal: Food Secure Canada. Retrieved from https:// foodsecurecanada.org/sites/foodsecurecanada.org/
files/DP10_Food_Democracy_and_Governance_0. pdf

Freire, P. (2000). Pedagogy of the oppressed: 30th anniversary edition. New York, NY: Continuum.

Gaventa, J., \& Bivens, F. (2014). Co-constructing democratic knowledge for social justice: Lessons from an international research collaboration. In J. Shefner, $\mathrm{H}$. F. Dahms, R. E. Jones, \& A. Jalata (Eds.), Social justice and the university: Globalisation, human rights and the future of democracy (pp. 149-174). New York, NY: Palgrave Macmillan.

Gaventa, J., \& Cornwall, A. (2006). Challenging the boundaries of the possible: Participation, knowledge and power. IDS Bulletin, 37(6), 122-128. https://doi. org/10.1111/j.1759-5436.2006.tb00329.x

Goodman, D., DuPuis, E. M., \& Goodman, M. K. (2012). Alternative food networks: Knowledge, practice and politics. Abingdon: Routledge.

Hall, B. (2011). Towards a knowledge democracy movement: Contemporary trends in communityuniversity research partnerships. Rizoma Freireano, 9(2011), 1-18.

Hall, B. L., \& Tandon, R. (2017). Decolonization of knowledge, epistemicide, participatory research and higher education. Research for All, 1(1), 6-19.

Harper, A., Shattuck, A., Holt-Giménez, E., Alkon, A., \& Lambrick, F. (2009). Food policy councils: Lessons learned. Oakland, CA: Institute for Food and Development Policy.

Hassanein, N. (2003). Practicing food democracy: A pragmatic politics of transformation. Journal of Rural Studies, 19(1), 77-86.

Hassanein, N. (2008). Locating food democracy: Theoretical and practical ingredients. Journal of Hunger \& Environmental Nutrition, 3(2/3), 286-308.

Haysom, G. (2014). Food system governance for urban sustainability in the global south. (Doctoral thesis). University of Cape Town, Cape Town, South Africa.

International Social Science Council, Institute of Development Studies, \& UNESCO. (2016). World social science report 2016-Challenging inequalities: Pathways to a just world. Paris: UNESCO. Retrieved from https://espas.secure.europarl.europa.eu/orbis/sites/ default/files/generated/document/en/245825e.pdf

Kent, G. (2011). Ending hunger worldwide. New York, NY: Routledge.

Kloppenburg, J. R., Hendrickson, J., \& Stevenson, G. W. (1996). Coming in to the foodshed. Agriculture and Human Values, 13(3), 33-41.

Levidow, L., Pimbert, M., \& Vanloqueren, G. (2014). Agroecological research: Conforming-Or transforming the dominant agro-food regime? Agroecology and Sustainable Food Systems, 38(10), 1127-1155.

Lucio-Villegas, E. (2016). Building knowledge democracy from the university: A case study in Spain. Action Research, 14(1), 3-18.

Martínez-Torres, M. E., \& Rosset, P. M. (2014). Diálogo de saberes in La Vía Campesina: Food sovereignty 
and agroecology. Journal of Peasant Studies, 41(6), 979-997.

Massey, D. (1991). A global sense of place. Marxism Today, 35(6), 24-29.

Matacena, R. (2016). Linking alternative food networks and urban food policy: A step forward in the transition towards a sustainable and equitable food system? International Review of Social Research, 6(1), 49-58.

Méndez, V. E., Bacon, C. M., \& Cohen, R. (2013). Agroecology as a transdisciplinary, participatory, and actionoriented approach. Agroecology and Sustainable Food Systems, 37(1), 3-18.

Meyer, G., \& Lindow, M. (2016). Food (r)evolution photo exhibition activates partnerships and conversations. Centre for Complex Systems in Transition. Retrieved from https://www0.sun.ac.za/cst/news/ food-revolution-photo-exhibition/

Millican, J., \& Hart, A. (2011). Community university partnership research in practice at the University of Brighton, England. Processes and pitfalls. Rizoma Freireano, 9(2011), 1-15.

Moolman, J. (2017). Cutting carrots the wrong way: Poetry and prose about food from the University of the Western Cape creative writing programme. Bellville: University of the Western Cape.

Murphy, S. (2008). Globalization and corporate concentration in the food and agriculture sector. Development, 51(4), 527-533.

Ncube, B. (2018). Insights into indigenous knowledge strategies for coping and adapting to drought in agriculture: A Karoo scenario, South Africa. Indilinga Knowledge Systems, 17(1), 92-108.

Norwood, F. B. (2015). Understanding the food democracy movement. Choices, 30(4), 1-5.

Nowotny, H. (2003). Democratising expertise and socially robust knowledge. Science and Public Policy, 30(3), 151-156.

Nowotny, H., Scott, P., \& Gibbons, M. (2001). Re-thinking science: Knowledge and the public in an age of uncertainty. Cambridge: Polity Press.

Nowotny, H., Scott, P., \& Gibbons, M. (2003). Introduction: Mode 2 revisited-The new production of knowledge. Minerva, 41(3), 179-194.

Openjuru, G. L., Jaitli, N., Tandon, R., \& Hall, B. (2015). Despite knowledge democracy and community-based participatory action research: Voices from the global south and excluded north still missing. Action Research, 13(3), 219-229.

Oswald, K. (2016). Interrogating an engaged excellence approach to research (Evidence Report No. 214). Brighton: Institute of Development Studies. Retrieved from https://opendocs.ids.ac.uk/opendocs/ bitstream/handle/123456789/12685/ER214_ InterrogatinganEngagedExcellenceApproachto Research.pdf?sequence $=1$ \&isAllowed $=y$

Oswald, K. (2017). Engaged excellence in research...another buzz phrase or an opportunity. Insti- tute of Development Studies. Retrieved from https:// www.ids.ac.uk/opinions/engaged-excellence-inresearchanother-buzz-phrase-or-an-opportunity

Oswald, K., Gaventa, J., \& Leach, M. (2016). Introduction: Interrogating engaged excellence in research. IDS Bulletin, 47(6), 1-17.

Pereira, L., \& Ruysenaar, S. (2012). Moving from traditional government to new adaptive governance: The changing face of food security responses in South Africa. Food Security, 4(1), 41-58.

Preiser, R., Hamann, M., \& Biggs, R. (2017). ARThropocene: Re-imagining anthropocene futures through art-science collaboration. Paper presented at Resilience 2017 Conference, Stockholm, Sweden.

Pulker, C. E., Trapp, G. S. A., Scott, J. A., \& Pollard, C. M. (2018). What are the position and power of supermarkets in the Australian food system, and the implications for public health? A systematic scoping review. Obesity Reviews, 19(2), 198-218.

Santos, B. D. (2006). The rise of the global left: The world social forum and beyond. London: Zed Books.

Schiff, R. (2008). The role of food policy councils in developing sustainable food systems. Journal of Hunger \& Environmental Nutrition, 3(2/3), 206-228.

Stones, L. (2018). Theatre review-Another one's bread: Comedy packed with social commentary and political barbs. Daily Maverick. Retrieved from https://www.dailymaverick.co.za/article/2018-0115-theatre-review-another-ones-bread-comedypacked-with-social-commentary-and-politicalbarbs/

Sustainable Livelihood Foundation. (2016). The heart of the matter. Cape Town: Sustainable Livelihood Foundation. Retrieved from http://livelihoods.org.za/wpcontent/uploads/2018/05/The_Heart_of_the_ Matter_Photobook.pdf

Tandon, R., Singh, W., Clover, D., \& Hall, B. (2016). Knowledge democracy and excellence in engagement. IDS Bulletin, 47(6), 19-36.

Tengo, M., Brondizio, E. S., Elmqvist, T., Malmer, P., \& Spierenburg, M. (2014). Connecting diverse knowledge systems for enhanced ecosystem governance: The multiple evidence base approach. Ambio, 43(5), 579-591.

Tremblay, C., \& Jayme, B. D. O. (2015). Community knowledge co-creation through participatory video. Action Research, 13(3), 298-314.

Visvanathan, S. (2009). The search for cognitive justice. Seminar. Retrieved from http://www.india-seminar. com/2009/597/597_shiv_visvanathan.htm

Welsh, J., \& MacRae, R. (1998). Food citizenship and community food security: Lessons from Toronto, Canada. Canadian Journal of Development Studies/Revue canadienne d'études du développement, 19(4), 237-255.

Wenger, E. (2000). Communities of practice and social learning systems. Organization, 7(2), 225-246.

Western Cape Government. (2016). Western Cape 
government household food and nutrition security strategic framework. Cape Town: Western Cape Government. Retrieved from https://www.westerncape. gov.za/sites/www.westerncape.gov.za/files/assets/ 140916_wcg_household_food_and_nutrition_ security_strategic_framework.pdf

Weymans, W. (2010). Democracy, knowledge and cri- tique: Rethinking European universities beyond tradition and the market. London Review of Education, 8(2), 117-126.

Wezel, A., \& Soldat, V. (2009). A quantitative and qualitative historical analysis of the scientific discipline of agroecology. International Journal of Agricultural Sustainability, 7(1), 3-18.

\section{About the Author}

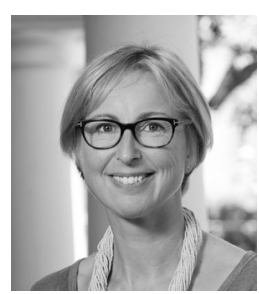

Camilla Adelle is a Senior Researcher at the Centre for the Study of Governance Innovation and the Centre of Excellence for Food Security at the University of Pretoria, South Africa. Her work focuses on stakeholder engagement and the co-production of knowledge for food governance. 